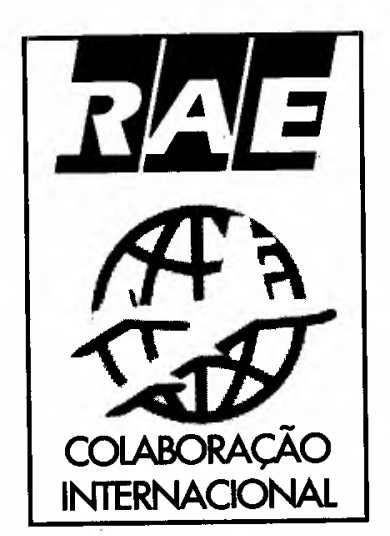

\title{
AUTOMATIZAR/INFORMATIZAR: AS DUAS FACES DA TECNOLOGIA INTELIGENTE
}

A tecnologia de informação, baseada nos computadores, está proporcionando uma nova infra-estrutura para várias atividades produtivas e comunicativas de vital importância para a vida organizacional.

Advanced computer-based information technology is providing a new infrastructure that mediates many of the productive and communicative activities most central to organizational life.

\section{PALAVRAS-CHAVE:}

Automatização, informatização,

qualificação, taylorismo.

\section{KEY WORDS:}

Automate, Informate, skills, taylorism.

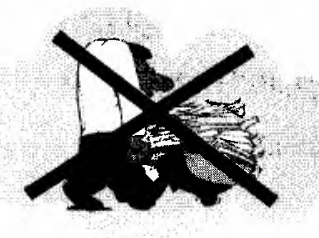

$$
\text { laylorism. }
$$

ש̂̀-

* Professora de Comportamento Organizacional e Administraçăo de Recursos Humanos na Universidade de Harvard. 
Coloque seu olho num caleidoscópio e segure-o contra a luz. Você verá uma explosão de minúsculos fragmentos coloridos numa composição intrincada. Imagine uma mão girando o caleidoscópio lentamente até que centenas de ângulos entrem em colapso, juntem-se e separem-se para formar um novo desenho. Uma mudança fundamental na infra-estrutura tecnológica das organizações exerce o poder da mão que gira lentamente o caleidoscópio. A tecnologia define o horizonte de nosso mundo material porque define os limites do possível e do imaginável: ela altera suposições sobre a natureza de nossa realidade, o padrão em que vivemos; e cria novas alternativas. Uma inovação como a máquina a vapor, o telefone, a luz elétrica ou o computador não é somente um elemento dentro do padrão; é uma força que gira o caleidoscópio, uma presença concreta que evoca silenciosamente uma nova visão do potencial de relacionamento e, finalmente, proporciona a ocasião para um novo padrão.

É nesse sentido que a tecnologia não pode ser considerada neutra. Ela é repleta de valência e especificidade nas oportunidades que cria e exclui. As viagens aéreas nos permitiram conquistar o tempo e a distância, unindo o planeta de uma nova forma e nos dando acesso a outras pessoas, lugares e culturas. A luz elétrica liberou a noite da escuridão. $O$ telefone nos permite contatos íntimos, sem que corpos se toquem ou olhares se cruzem. A ladainha das novas e dramáticas organizações da realidade engendradas pelas novas tecnologias é bem extensa.

Entretanto, entre o girar do caleidoscópio e o surgimento de um novo padrão, uma outra força dá sentido à configuração final dos elementos. Essa força é a atividade humana da escolha. À medida que os limites do possível são redefinidos, a oportunidade de escolha também é multiplicada. Devo pegar um avião, ir de carro ou de trem? Qual é o meu destino? Devo usar o telefone para manter um contato íntimo com amigos que eu raramente vejo? Em caso afirmativo, a quem devo telefonar, com que freqüência e por quanto tempo devemos conversar? Portanto, a metáfora da mudança do caleidoscópio é limitada. Os lindos fragmentos alinham-se aleatoriamente, mas a mudança nas sociedades humanas não é assim tão cega. Em- bora as intenções não predigam necessariamente as conseqüências, as ações dos seres humanos se baseiam na construção de significados, na avaliação de interesses e, com variados graus de consciência, em escolhas. É no domínio da escolha que a tecnologia revela um certo indeterminismo. Embora redefina o horizonte de possibilidades, ela não pode determinar quais escolhas serão feitas e com que intenções.

Nessas últimas décadas do século $X X$, várias hipóteses duradouras, sobre a organização do trabalho, estão sendo contestadas por uma nova presença tecnológica. A tecnologia da informação, baseada nos computadores, está proporcionando uma nova infra-estrutura para várias atividades produtivas e comunicativas de vital importância para a vida organizacional. Este artigo examina o papel que a tecnologia da informação pode desempenhar na reestruturação do local de traba1ho. Entrevistamos aproximadamente 500 trabalhadores e administradores em dez locais de pesquisa que representam seis companhias, em setores tão diversos como bancos, companhias de telecomunicações e produtores de papel e celulose. Vamos discutir alguns assuntos que atravessam as fronteiras organizacionais e que parecem ter relevância para uma vasta gama de situações. Este artigo vai esboçar, especificamente, duas concepções divergentes da tecnologia da informação e suas implicações para a organização do trabalho.

\section{AUTOMATIZAR/INFORMATIZAR: A DUALIDADE DA TECNOLOGIA INTELIGENTE}

Quando a lógica da administração científica de Frederick Taylor começou a tomar corpo no começo deste século, a substituição do trabalho humano pela força da máquina tornou-se a solução óbvia para o aumento da velocidade e do volume de produção. Começando em 1915 pela fábrica de automóveis da Ford, em Highland Park, seriam confiadas à tecnologia a complementação ou a superação da direção humana. Em Mechanization takes command, Siegfried Giedion descreve esse processo: "Os cartões de instrução que Taylor tanto valorizava, Ford pôde descartar. A linha de montagem, as plataformas volantes, os trilhos suspensos e as esteiras rolantes para material tomaram seu lugar... A análise dos movimentos tornou-se desnecessária, já que as 


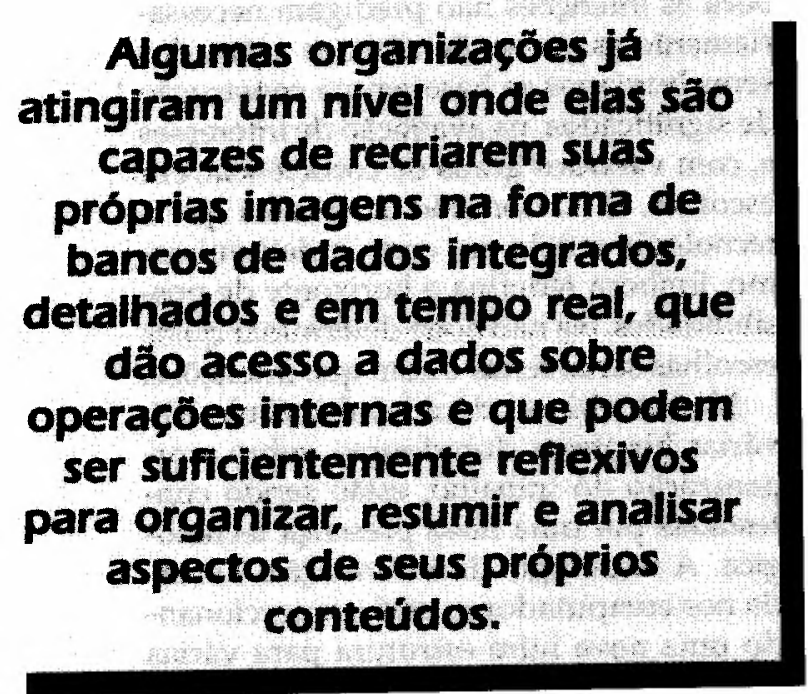

tarefas do operário da linha de montagem ficaram reduzidas a algumas poucas manipulações. Mas o cronômetro de Taylor permaneceu, medindo o tempo das operações em frações de segundo."

H. L. Arnold, um jornalista industrial, escreveu com entusiasmo sobre as inovações de Ford que maximizavam a continuidade da montagem. Ele resumiu os principais elementos dessa estratégia de produtividade: inicialmente, todos os movimentos desnecessários foram eliminados das ações dos trabalhadores; em seguida, a tarefa era organizada para requerer o "mínimo de consumo de força de vontade e esforço mental." Essa fórmula é de uma significância duradoura, pois tem dominado o planejamento das tecnologias de produção de massa através do século $X X$. Ela exige uma simplificação (e, algumas vezes, intensificação) dos esforços, enquanto a qualificação é, cada vez mais, incorporada pela tecnologia.

Nos anos 80 , o rápido desenvolvimento e a difusão da tecnologia avançada da informação focalizaram a atenção novamente sobre a lógica subjacente do desenvolvimento da tecnologia. Em que medida as aplicações dessa nova e poderosa tecnologia reproduzem a fórmula da substituição do trabalho, que foi aperfeiçoada através de décadas de sucesso econômico nas indústrias de produção de massa?

Os administradores, em geral, investem em novas tecnologias de informação porque acreditam que isso lhes permitirá realizar suas operações mais rapidamente $e$ a um custo mais baixo. Os administrado- res estão começando a apreciar, cada vez mais, as formas complexas pelas quais as novas tecnologias podem proporcionar novas fontes de vantagens competitivas. Em ambos os casos, quando os administradores utilizam a tecnologia da informação para seus objetivos estratégicos, eles geralmente planejam alcançar um ou mais dos três objetivos operacionais independentes: aumentar a continuidade (integração funcional, automação intensificada, resposta rápida), o controle (precisão, acuidade, previsibilidade, consistência, certeza) e a compreensibilidade (visibilidade, análise, síntese) das funções produtivas.

Num ambiente manufatureiro, por exemplo, dispositivos baseados em microprocessadores, como controladores lógico-programáveis (CLPs) ou sensores, podem ser integrados a equipamentos de produção e conectados a um sistema hierarquizado de computadores, aumentando, assim, tanto a continuidade, como o controle das operações de produção. Num escritório, a padronização, a atualização de dados em tempo real e a armazenagem ordenada do histórico das transações possibilitadas pelos computadores reforçaram o controle e a continuidade das funções do escritório.

A tecnologia da informação também aumenta a compreensibilidade dos próprios processos automatizados. Na verdade, uma maior compreensão é tanto uma condição, como uma conseqüência de tais aplicações. Qualquer atividade, de uma transação de escritório a uma operação de pintura de automóvel, para ser computadorizada, deve primeiro ser fragmentada e analisada em seus componentes menores, de forma a ser traduzida na linguagem binária de um sistema de computadores. Para a maioria das organizações, esse passo prepara o caminho para a automação e cria, simultaneamente, uma compreensão mais profunda da atividade em si mesma. Uma vez automatizadas, as informações sobre os dispositivos próprios que aumentam o controle ou a continuidade geram novos fluxos de dados que proporcionam uma oportunidade para desenvolver uma compreensão ainda mais profunda da operação. Por exemplo, CLPs ou sensores que utilizam microprocessadores não só aplicam instruções programadas aos equipamentos; eles também 
convertem o estado atual do produto ou do processo em dados, criando, assim, a possibilidade de uma maior compreensão. Da mesma forma, os mesmos sistemas que tornam possível a automação das transações nos escritórios criam uma visão geral do funcionamento em tempo real da organização e coordenam vários níveis de dados que, então, ficam disponíveis para serem acompanhados, reportados e analisados.

Portanto, por sua própria natureza, a tecnologia da informação é caracterizada por uma dualidade fundamental que ainda não foi completamente avaliada. Primeiro, a tecnologia pode ser utilizada para automatizar operações. $O$ raciocínio atrás de tais aplicações é essencialmente o mesmo aplicado na fábrica de montagem de automóveis de Ford. O objetivo é substituir o esforço e a qualificação humanos por uma tecnologia que permita que os mesmos processos sejam executados a um custo menor, com mais controle e continuidade.

Segundo, a tecnologia pode ser usada para criar informações. Mesmo quando uma dada aplicação visa a automatizar, ela simultaneamente gera informações sobre os processos que estão por trás e através dos quais uma organização realiza seu trabalho. A palavra que uso para descrever esse processo é informatizar. Ela capta esse aspecto da tecnologia que pode não só incluir, mas também ir além da automação. Vemos o poder informatizante da tecnologia inteligente numa indústria quando dispositivos baseados em microprocessadores como robôs, CLPs ou sensores, traduzem o processo produtivo de três dimensões em dados digitais bidimensionais. Tais dados são, então, geralmente colocados à disposição em terminais de vídeo ou em listagens de computador, na forma de símbolos eletrônicos - números, letras e gráficos. Estas são informações que não existiam anteriormente. No ambiente dos escritórios a combinação de sistemas de transação on-line e sistemas de comunicação cria uma vasta quantidade de informações que inclui muitos dados que anteriormente eram armazenados na cabeça das pessoas, em conversas face a face, em diferentes gavetas de arquivos e em vários pedaços de papéis amplamente dispersos no tempo e no espaço. Na sua capacidade de automatizar, a tecnologia da informação tem uma habilidade prodigiosa de eliminar o esforço humano e substituir boa parte do que era conhecido como qualificação humana. Como uma tecnologia informatizante, suas implicações são igualmente significativas, embora ainda não bem compreendidas.

A tecnologia da informação pode contribuir intensamente para os objetivos de aumento do controle e da continuidade, mas sua singularidade reside na sua capacidade de informatizar, que pode aumentar a compreensão das operações através das quais uma organização realiza seu trabalho. Até aqui apresento esse processo informatizante como se ele fosse autônomo e não intencional. Todavia, uma organização pode decidir enfatizar e explorar o potencial informatizante da tecnologia da informação. A extensão da ênfase dada a cada uma das duas capacidades da tecnologia da informação desempenhará um papel central na determinação das conseqüências organizacionais da mudança tecnológica. A escolha é, sobretudo, uma questão de estratégia e deriva da concepção que a gestão possui da contribuição que essa tecnologia pode trazer para os negócios. A informatização pode acontecer como uma conseqüência inesperada, $e$ não administrada, da automação baseada nos computadores, mas pode ser parte de uma política consciente visando a explorar a presença de novas informações e criar um conhecimento mais profundo, mais amplo e perspicaz dos negócios. Isso, por sua vez, pode servir como catalisador para aperfeiçoar e inovar a produção e o fornecimento de bens e serviços, fortalecendo, assim, a posição competitiva da companhia.

No entanto, embora os administradores já estejam começando a reconhecer e apreciar o poder informatizante da nova tecnologia, uma abordagem estratégica do emprego da tecnologia, em muitos casos, não vai alcançar os resultados desejados. Uma conclusão de minhas pesquisas é que, se uma empresa deseja aproveitar ao máximo o processo de informatização, são necessárias inovações organizacionais para sustentar as inovações tecnológicas. É um processo que tem implicações para os tipos de qualificações que os membros de uma organização devem desenvolver para a articulação de papéis e funções e para o desenho de sistemas e estruturas 
de apoio e recompensa à participação numa organização informatizada.

\section{O BANCO DE DADOS COMO SUBSTITUTO DA ORGANIZAÇÃO}

À medida que as organizações aplicam a tecnologia da informação, elas tendem a desenvolver mecanismos que permitem que informações sejam automaticamente geradas e captadas. Quando a automação continua, elas procuram meios para integrar as informações e torná-las válidas, imediatas e acessíveis. Algumas organizações já atingiram um nível em que são capazes de recriar suas próprias imagens na forma de bancos de dados integrados, de-

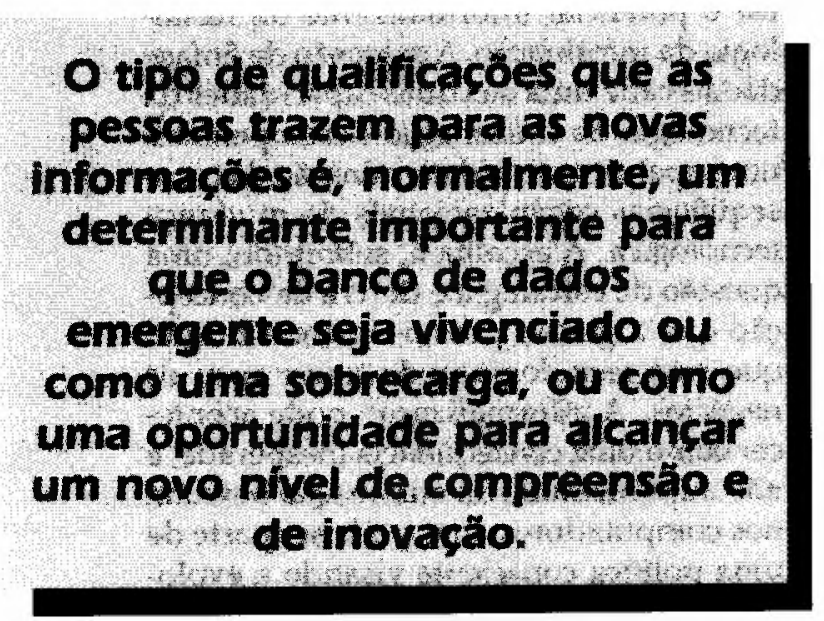

talhados e em tempo real, que dão acesso a informações sobre operações internas e externas e que podem organizar, resumir e analisar aspectos de seus próprios conteúdos. Numa organização altamente informatizada, os bancos de dados assumem vida própria. Tornam-se um domínio autônomo, um símbolo público de experiência organizacional, que anteriormente era fragmentada, privada e implícita. Por exemplo, numa fábrica de papel altamente automatizada, construída em torno de instrumentos baseados em microprocessadores, um banco de dados computadorizado incluía todos os negócios vitais, os dados de pessoal, assim como os registros de todas as operações em tempo real - criados por medições periódicas das 2.500 peças dos equipamentos da fábrica, que eram atualizadas muitas vezes por minuto. Um sistema de informação, tão poderoso como esse, torna-se um substi- tuto simbólico, on-line, da maioria dos detalhes dinâmicos da vida cotidiana de uma organização. $O$ fato de que um banco de dados assume o status de substituto da organização é ainda mais compulsivo no contexto de organizações que tradicionalmente utilizam intensamente as informações: bancos, companhias de seguros, companhias aéreas etc. Efetivamente, num discurso recente, o presidente da $\mathrm{MCI} \mathrm{Co}-$ municações, referindo-se às recentes mudanças nos serviços financeiros, afirmou que "os bancos estão se transformando em banco de dados."

Mas o que significa para uma organização "transformar-se num banco de dados?" Em organizações onde a informatização ocorre como um fenômeno subadministrado e autônomo, o crescimento dos bancos de dados é vivenciado como esmagador e incompreensível - daí o termo sobrecarga de informação. Uma abordagem do emprego da tecnologia que supõe qualificações mínimas na interface da informação, com uma divisão do trabalho fragmentada e hierárquica, tende a criar organizações com uma capacidade mínima de utilizar as novas informações disponíveis de forma a adicionar valor aos negócios.

Quando o processo de informatização é perseguido como parte de uma estratégia consciente, a nova presença da informação pode ser sentida em cada nível de atividade da organização. A presença da informação convida os membros da organização a levantar questões e a gerar hipóteses. Como aspectos do funcionamento da organização são trazidos à luz ou vistos de diferentes maneiras, novas percepções são engendradas. A organização pode se transformar num ambiente de aprendizado onde o trabalho em si tornase um processo de investigação e as contribuições que seus membros podem dar são, cada vez mais, uma função de sua capacidade de perceber, refletir, explorar, formular hipóteses, testar e comunicar.

\section{O DOMÍNIO DA INTERFACE DA INFORMAÇÃO}

O tipo de qualificação que as pessoas trazem para as novas informações é, normalmente, um determinante importante para que o banco de dados emergente seja vivenciado, ou como uma sobrecarga, ou como uma oportunidade para alcançar um 
novo nível de compreensão e de inovação. Minha compreensão dessa nova necessidade de qualificações deriva de entrevistas detalhadas com pessoas que têm se deparado com a necessidade de entender seu trabalho, quando informações sobre suas tarefas chegam a elas, basicamente, através de um sistema baseado em computadores.

O domínio da interface da informação depende do que eu defino como qualificação intelectiva. O problema central da pessoa que precisa realizar uma parcela significativa do seu trabalho através da interface da informação é o da referência. As pessoas se perguntam " $A$ que esses $d a-$ dos se referem? O que significam?" As qualificações intelectivas tornam-se necessárias para entender e enfrentar o problema da referência.

A qualificação intelectiva tem três dimensões cruciais. A primeira é a capacidade de pensar abstratamente. Para muitas pessoas - como o operador de fábrica que interagia diretamente com a maquinaria, o pessoal de escritório cujas tarefas envolviam pedaços de papel específicos e rotinas interpessoais ou o administrador que selecionava informações em encontros e conversas com as pessoas - tarefas de trabalho costumavam estar embutidas em atividades concretas. Mas quando o trabalho se torna mais mediado pelo computador, ele também se torna mais abstrato e distante de referências físicas. Aprender o que a informação pode significar quando está separada de seu contexto de ação, requer uma nova ênfase no pensamento abstrato e depende da capacidade de tornar explícitas as inferências que ligam os dados ao mundo concreto. Um operador de uma fábrica automatizada descreveu sua experiência numa sala de controle automatizada: "Sempre que apertar um botão, você tem que ter em mente exatamente o que vai acontecer. Você precisa ter na sua cabeça onde está, o que está fazendo e porque está fazendo aquilo. Na fábrica, você pode saber das coisas apenas pelo hábito, sem saber que sabe. Aqui, você tem que olhar os números; ao passo que lá você tem que olhar o próprio processo."

O segundo componente da qualificação intelectiva é o raciocínio indutivo. Como a informação num sistema de computador tende a ser reduzida a termos quantitativos, as pessoas devem ser capazes de abordar dados analiticamente, compreender as relações potenciais entre as variáveis e usar os dados para construir e testar hipóteses. Um engenheiro de sistemas, que tinha trabalhado próximo aos operadores numa outra fábrica altamente automatizada, descreveu como os bons operadores controlavam o processo produtivo através de uma interface de controle computadorizado: "Quando você quer saber o que está acontecendo em uma parte da fábrica, corre a vista por várias telas de dados. Você deve manter os dados importantes em sua mente enquanto continua a percorrer as informações. As pessoas aprendem a organizar os dados em suas mentes. Elas criam modelos mentais sobre o que está realmente acontecendo e provêem o modelo com dados até que tenham um quadro completo."

A capacidade de fazer esse raciocínio indutivo, finalmente, depende de se ter uma concepção teórica dos processos aos quais os dados se referem. Essa é a terceira dimensão da qualificação intelectiva; essa compreensão teórica é que proporciona um roteiro através dos dados, uma base a partir da qual geram-se hipóteses e dicas sobre onde buscar evidências das conseqüências de uma dada ação. Considere as palavras de um contabilista para quem um sistema de informação poderoso proporcionava, em tempo real, um resumo de sua carteira de empréstimos: "Algumas coisas podem ser menos evidentes porque há muita informação. Temos que gastar tempo indicando, com precisão, os principais fatores que estamos procurando. Você tem que saber o que é significativo para saber como distingui-lo." Ou, nas palavras de um operário de uma outra fábrica: "Quanto mais aprendo teoricamente, mais posso ver na informação. Dados brutos transformam-se em informação, com o meu conhecimento. Acho que você tem que ser capaz de saber mais. Sua compreensão do processo é que o orienta.

Naturalmente, as pessoas aprendem sobre e com seu trabalho de várias maneiras. Quando as tarefas tornam-se mediadas pelo computador, freqüentemente as pessoas vão procurar maneiras de conferir com as ações realizadas pré-computador para se assegurarem de que estão fazendo as coisas corretamente. Por exemplo, uma operação de escritório pode ser desempenhada dos modos manual e automatizado até que as pessoas confiem no novo sistema. Operários, algumas vezes, saem da sala de controle para confe- 
rir os equipamentos, só para ver se o sistema de computadores reflete precisamente o que está acontecendo. Entretanto, esses contextos mais antigos freqüentemente são organizados fora do novo ambiente - não se pode voltar para conferir porque não há para onde voltar. Os equipamentos e a instrumentação antigos estão desmontados; nos escritórios, os formulários e as rotinas construídos ao seu redor desapareceram. Quando isso acontece, a qualificação intelectiva torna-se um prérequisito para se operar, com competência, o novo ambiente mediado pelo computador. Aqueles que não a possuem podem se sentir perdidos.

\section{DOIS CAMINHOS DIVERGENTES}

Numa organização industrial, o gerente da fábrica teve um debate acalorado com suas lideranças sobre a concepção estratégica que iria orientar o emprego da tecnologia. "Vamos todos trabalhar para uma máquina inteligente", ele perguntou, "ou vamos ter pessoas inteligentes em torno de uma máquina?" A resposta para essa pergunta tornou-se a pedra fundamental de qualquer estratégia para desenvolver mutuamente aplicações tecnológicas e inovações organizacionais que lhes dêem suporte. Nesse contexto, "pessoas inteligentes" são membros das organizações que podem contribuir e aprender com os sistemas através dos quais executam seus trabalhos. Uma estratégia que enfatiza a automação concentra-se na máquina inteligente. Uma estratégia informatizante reconhece o valor e a função da máquina inteligente, mas somente no contexto de sua interdependência com as pessoas inteligentes. $\mathrm{E}$ o conhecimento e a compreensão na cabeça das pessoas suas qualificações intelectivas - que transformam as máquinas inteligentes numa oportunidade de melhorar fundamentalmente os negócios. $\mathrm{O}$ domínio da inferência, através do raciocínio indutivo e da compreensão teórica, proporciona a base a partir da qual aqueles que estão na interface da informação podem construir, integrar e sintetizar o significado da informação.
Talvez a razão mais forte que leva os administradores a dar uma ênfase restrita à automação seja a teia da lógica econômica na qual eles têm que operar. Fórmulas contábeis tradicionais tratam a tecnologia como substituição do trabalho pelo capital. Como inúmeros administradores sabem, "para justificar um computador, tem que se mostrar eliminação de empregos". Essas linhas de força econômica abrem um caminho profundo e têm algumas implicações inevitáveis. Por exemplo, recursos organizacionais são canalizados de modo a dar suporte à estratégia fundamental da tecnologia. Investimentos e conhecimentos são dedicados a aumentar a automação através da tecnologia, aplicativos, manutenção e aperfeiçoamentos. E um fato simples e óbvio que tais escolhas tenham conseqüências em termos de quais potencialidades organizacionais tornam-se robustas, atrofiam ou nascem mortas.

A ênfase na automação é reforçada pelo papel da média gerência, que tem sido definido como o de coletar, manipular, disseminar ou ocultar informações. À medida que as organizações crescem em tamanho, a média gerência torna-se a condutora da informação através da qual planejamento e execução podem ser coordenados e controlados. Entretanto, existe um significado mais profundo para a função de informação da gerência: administradores têm sido tradicionalmente considerados os representantes da propriedade. Eles seriam os únicos em quem se poderia confiar, em termos de lealdade e dedicação que esse investimento simbólico dos direitos da propriedade implica. Deriva-se daí que informações importantes só poderiam ser confiadas àqueles com quem se pode contar para servir aos interesses da propriedade. Mas o processo de informatização, desencadeado pela nova tecnologia, pode proporcionar a quem trabalha na interface da informação o acesso a dados sobre grande parte do funcionamento da organização. $\mathrm{O}$ vice-presidente de uma companhia coloca o problema da seguinte maneira: "Um aspecto que a tecnologia está nos forçando a encarar envolve a 
perda do controle gerencial.(...) Há uma definição legal que a administração é o feitor dos proprietários da companhia. Espera-se que eles sejam leais e totalmente empenhados em alcançar os objetivos dos proprietários. Eles são os responsáveis por nunca deixarem a situação sair do controle. (...) A nova tecnologia da informação introduz alguns novos problemas. De repente, o povo que trabalha com esses sistemas está interagindo com um poder tecnológico imenso - poder de ver todas as funções da operação. Isso é muito assustador para alguns administradores."

Para a média gerência que mede seu valor em termos da sua capacidade de exercer o controle e maximizar a certeza dos resultados, a escolha de criar "pessoas inteligentes" pode ser uma ameaça. Mesmo aqueles que estão dispostos a enxergar a obsolescência de suas funções tradicionais podem achar a ambigüidade do seu papel emergente muito dolorosa e opor resistência. Como um administrador explicou: "Quando nos defrontamos com a mudança, a grande questão é 'o que há para mim'? Se eu puder manter a situação estritamente definida, então conheço o meu valor como administrador. Não sei quais devem ser minhas novas qualificações e isso é desconfortável."

À medida que os administradores que enfatizam a automação confrontam esses dilemas, a estrutura do taylorismo provavelmente estará se repetindo com todos os seus antagonismos inerentes. Considere a fala de um trabalhador numa fábrica que tinha investido maciçamente em sistemas de controle automáticos: "Eles precisam dos trabalhadores para ajudá-los a determinar o que o computador deve fazer. Mas por que você deve dizer a um homem todo seu conhecimento sobre como este lugar funciona, para que ele o coloque dentro de uma máquina que vai, então, tirar seu trabalho? A máquina rouba minha dignidade, rouba o meu saber de como fazer... Se eles não gostam de mim, podem me dificultar a vida, porque sou mais dispensável agora, pois meu conhecimento está dentro do sistema." Ou, como um funcionário de escritório numa outra companhia colocou: "Como você está lidando com o terminal todos os dias, você não pode superá-lo. Você não pode ultrapassá-lo. Ele é somente um objeto inanimado que fica à sua mesa e você tem que lutar contra ele todos os dias. E o terminal vai controlar todo o seu trabalho... É como uma luta que você não pode ganhar. Contra o terminal, você não tem chances."

Sob essas condições, algumas conseqüências organizacionais tornam-se mais prováveis que outras. A produtividade vai aumentar, pelo menos a curto prazo, à medida que trabalhos rotineiros são eliminados. A autoridade tenderá a se tornar mais centralizada à medida que os administradores fixarem objetivos para a máquina. Os esforços no projeto tenderão a maximizar a capacidade de auto-regulação dos sistemas computadorizados e a minimizar a necessidade de interação, compreensão e contribuição humanas. Membros das elites administrativa e técnica provavelmente se tornarão mais poderosos à medida que terão as qualificações intelectivas necessárias para monitorar, melhorar ou ultrapassar os sistemas automáticos. Nesse cenário, a força de trabalho remanescente tende a se tornar um acessório ao sistema da máquina, com pouca ou nenhuma compreensão crítica do seu funcionamento. Tal dependência da automação significa que os problemas de confiabilidade serão críticos. Serão neces sários controles automáticos que possam proporcionar medidas infalíveis de proteção contra erros do sistema, uma vez que os efeitos ondulatórios de tais falhas podem se propagar numa velocidade alarmante em sistemas altamente automáticos e interdependentes.

Apesar das fortes exigências econômicas, organizacionais e psicológicas que pressionam os administradores a enfatizar exclusivamente as oportunidades de automatização oferecidas pelas tecnologias de informação, vários administradores com quem falei começavam a sentir que essa ênfase tendia a impedir que suas organizações utilizassem as novas informações geradas pelo sistema como uma oportunidade para a inovação e o aperfeiçoamento dos negócios.

Numa fábrica que estava mudando para um sistema de controle baseado num microprocessador que permitiria aos trabalhadores uma interação remota com o processo de produção através de uma interface de informação centralizada, um dos administradores reclamou: "Nós cortamos tanta gente que não há ninguém para fazer as coisas interessantes que poderíamos fazer com as informações. Precisamos analisar 
o valor adicionado e não sabemos como. Precisamos deixar o pessoal horista contribuir, mas nōo vamos sair da linha porque, no final das contas, o que nos interessa é o lucro. Infelizmente, ninguém está considerando os prós e contras."

A má consideração dos prós e contras envolve as características especiais de uma tecnologia informatizante. Enquanto a visão da tecnologia é limitada à redução de pessoal e caracterizada pela suposição de que mais tecnologia significa diminuição das necessidades de qualificação, então a capacidade de informatizaçấo da nova tecnologia não pode ser explorada. Pode ser verdade que o caminho mais rápido para o aumento dos lucros seja esse tipo

\section{Informatizar implica uma divisão do trabalho diferente da lógica da organização do trabalho herdada da administração científica, aperfeiçoada nas indústrias de produção em massa, e amplamente aplicada nas burocracias dos colarinhos brancos.}

de substituição de trabalho. Pode ser verdade, também, que para vários negócios a lucratividade, a inovação e o crescimento a longo prazo dependam de uma nova abordagem à utilização da tecnologia uma abordagem capaz de empregar "pessoas inteligentes" para explorar as oportunidades de vantagens competitivas oferecidas por mais, diferentes e melhores informaçôes.

Numa organização, os administradores seniores estavam tentando avaliar a experiência de seus envolvidos nos problemas da computadorização. Eles começaram a perceber que qualquer tentativa de aproveitar-se da espiral ascendente de informações disponíveis exigiria uma mudança organizacional muito mais profunda do que a que tinham cogitado seriamente até então. $\mathrm{O}$ vice-presidente de uma corporação refletiu: "Com as novas tecnologias parece que há um tipo de desenvolvimento qua- se inevitável, se você tem como objetivo maximizar todas as suas variáveis de negócios e usar toda a organização para contribuir nesse esforço. Eu agora penso que é preciso distribuir a informação e a autoridade de uma nova maneira para alcançar isso. Caso contrário, você vai abrir mão de um componente importante de sua vantagem competitiva."

Supondo-se que a disponibilidade de novas aplicações vai rapidamente igualar qualquer vantagem competitiva ganha pelo fato de ter sido um líder na tecriologia, segue-se, então, que uma vantagem permanente provavelmente virá da capacidade de uma organização de explorar as oportunidades de aprendizado oferecidas pelas novas informações. Em vários negócios, melhorias e inovações em produtos e serviços, possibilitadas pelo aumento dos níveis de compreensão e entendimento, podem ser uma contribuição importante para uma posição competitiva. Essas organizações vão se distinguir pela exploração do potencial de informatização das novas tecnologias. Por exemplo, um ban$\mathrm{co}$, no processo de criação de um banco de dados on-line e integrado para proporcionar números válidos e internamente consistentes, para as operações, tanto de frente, como de retaguarda do banco, viu o novo "ambiente de banco de dados" como fonte de desenvolvimento de novos produtos. Produtos de bancos eram redefinidos em função de seu conteúdo informacional e dos procedimentos usados para analisar essa informação. A expectativa era que tal banco de dados proporcionasse a flexibilidade necessária para se manipular esses dados de formas diferentes - e, assim, criar novos produtos. Como um executivo de banco explicou: " $80 \%$ dos produtos do banco podem ser produzidos com 150 procedimentos. Os outros $20 \%$ dos produtos requerem uma mesma quantidade de procedimentos. Nós queremos um banco de dados que nos dê todas as peças - uma visão integrada do nosso negócio por completo. Será como a visão de um quadro do banco. Então, qualquer idéia que possamos ter pode ser convertida imediatamente em produto. Se você usa o mesmo procedimento numa ordem diferente, você obtém um produto diferente ou você pode eliminar um procedimento e obter um novo produto. Isso nos dará um banco verdadeiramente flexível. O desafio será o de treinar o nosso pessoal a pensar os produtos como algo de conceitual e não material. O nosso negócio 
dependerá dos dados, dos procedimentos e do pensamento conceitual, para sugerir novas idéias."

Para que essa visão dê frutos, cada nível da organização deve receber o poder de responder efetivamente às informações que são mais relevantes para seus aspectos funcionais. Essa delegação de poder depende de dois elementos. Em primeiro lugar, aqueles que estão mais próximos das informações relevantes para suas funções devem ter a autoridade de responder. Tal autoridade só vai emergir a partir de uma estratégia que realce a importância de pessoas inteligentes. Isso implica e reflete uma segunda necessidade - que a organização faça um compromisso com o desenvolvimento das qualificações intelectivas na interface da informação. Sem. um aprofundamento dessas qualificações, as pessoas não serão capazes de se empenhar na qualidade de "fazer sentido" que pode adicionar valor. Como um trabalhador numa fábrica recentemente automatizada reflete: "Antes, nós não tínhamos nenhum meio para saber o que estávamos aprendendo ou para compreender o efeito de nossas ações. Agora, temos tanta informação e feedback que não ser capaz de conceitualizá-las é um verdadeiro crime."

\section{UMA NOVA DIVISÃO DO TRABALHO}

Informatizar implica uma divisão do trabalho diferente da lógica da organização do trabalho herdada da administração científica, aperfeiçoada nas indústrias de produção em massa e amplamente aplicada nas burocracias dos colarinhos brancos. Com a administração científica, o saberfazer implícito dos trabalhadores era analisado para gerar dados que podiam servir como base para o desenvolvimento de uma série de funções administrativas. Essas funções permitiram que a administração assumisse a responsabilidade pela coordenação e controle do processo de produção, incluindo a fragmentação e a padronização das tarefas.

Quando uma tecnologia inteligente cria (ou proporciona um novo acesso a) informações, e essas informações tornam-se disponíveis aos que estão na produção, a lógica essencial do taylorismo é despedaçada. Pela primeira vez a tecnologia devolve aos trabalhadores o que ela havia tirado e muito mais ainda. O saber operá- rio estava implícito em suas ações. A informatização torna esse saber explícito; ela é um espelho refletindo o que era tacitamente conhecido, mas agora está numa forma que é pública e precisa. Ela também expande os limites do que se pode saber, uma vez que as novas informações disponíveis freqüentemente transpõem as fronteiras estreitas da definição convencional do cargo. A qualificação intelectiva tornase o meio pelo qual pode-se reapropriar e expandir o próprio saber e engajar-se num tipo de processo de aprendizagem que torna a informação valiosa. Como um trabalhador numa fábrica colocou: "Toda informação que você pode obter através desse sistema dá uma oportunidade de ver como as coisas podiam ter sido feitas melhor ou como elas podiam ser feitas diferentemente... Esse é o potencial real desse equipamento. Isso nunca teria acontecido se nós tivéssemos ficado com a tecnologia antiga."

A informatização evoca uma nova visão da organização: um grupo de pessoas reunidas em torno de um núcleo central - que é o banco de dados automatizado. Os indivíduos se relacionam com a interface da informação eletrônica segundo suas responsabilidades, que variam em extensão e amplitude. A qualificação intelectiva torna-se um dos recursos mais preciosos da organização e a companhia investe na manutenção e na melhoria desse banco de qualificações em medidas comparáveis ao investimento em tecnologia propriamente dita. Nessa visão, a organização torna-se uma instituiçãó de aprendizado para a qual um objetivo fundamental é a expansão do saber sobre os negócios e as oportunidades que se apresentam. Essa abordagem implica uma mudança em relação às práticas mais còrentes. Hoje, não é raro que uma organização gaste milhões na compra e na instalação de tecnologia, enquanto que nem o mais rudimentar treinamento consegue aparecer como um item no orçamento anual.

Administradores que querem prosseguir com essa visão precisarão avaliar as complicações da vida na interface da informação. Muito freqüentemente, pressupõe-se que os seres humanos vão responder à apresentação de dados como servomecanismos obedientes, reconhecendo imediatamente o significado dos dados e respondendo adequadamente. Entretanto, 
a imagem do sujeito humano como um outro fator no ciclo do feedback não é realista. $O$ significado que as pessoas atribuem a seu trabalho, seus níveis de motivação e envolvimento e o tipo de qualificação que possuem vão mediar a relação entre a interface da informação e o observador humano.

$\mathrm{Na}$ verdade, à medida que o trabalho e o esforço que as pessoas devem fazer tornam-se mais abstratos, a necessidade de motivação torna-se ainda mais crucial. Para os administradores de linha de frente, as contingências da supervisão são alteradas. Num ambiente convencional é relativamente fácil para um administrador determinar que um operário não consertou adequadamente uma caldeira (ela continua funcionando mal) ou não digitou um documento adequadamente (ele está cheio de erros). Mas como um administrador determina se um empregado não respondeu a um elemento dos dados? Como um administrador avalia a possibilidade de oportunidades perdidas de se aprender mais sobre os negócios ou melhorar as operaçōes de alguma maneira? Em última análise, somente a qualificação e o compromisso do empregado podem garantir que um esforço intelectivo será realizado e que as oportunidades proporcionadas por uma tecnologia informatizante serão exploradas.

Nós permanecemos, nesses últimos anos do século vinte, prisioneiros de uma linguagem que tem suas raizes num estilo de vida e de trabalho que estão se tornando rapidamente obsoletos.

\section{UMA NOVA LINGUAGEM E UMA NOVA VISÃO}

Qualquer pessoa aplicando uma estratégia informatizante enfrentará uma variedade de barreiras organizacionais, algumas das quais foram identificadas nesta discussão. Essas barreiras são apenas uma parte do problema; um aspecto mais pro- fundo a ser confrontado, que é de caráter filosófico e ideológico, envolve as limitações da linguagem. Nós permanecemas, nesses últimos anos do século $X X$, prisioneiros de uma linguagem que tem suas raízes num estilo de vida e de trabalho que estão se tornando rapidamente obsoletos. Considere o vocabulário usual dos postos de trabalho: administradores requerem trabalhadores; superiores têm subordinados; cargos têm definições específicas, detalhadas, estritas e, em termos de tarefas, organizações têm níveis que, por sua vez, criam cadeias de comando e amplitude do controle que são centralizadas ou descentralizadas. As metáforas-guia são militares; as relações são contratuais e, freqüentemente, antagonistas; a imagem fundamental é a de uma empresa industrial em que as matérias-primas são transformadas, através do trabalho físico e da força da máquina, em bens acabados. Como a produção é complexa, cara e algumas vezes perigosa, a idéia que prevalece é a de que ela necessita de um tipo preciso de planejamento e direção que somente a estrutura administrativa pode proporcionar.

Para algumas organizaçōes, devido à natureza de seus produtos, processos ou mercados, essa abordagem continuará a ser a mais apropriada. Mas, para muitas outras, o sucesso organizacional dependerá menos da execução eficaz do status quo, do que de uma melhor compreensão das funções, de inovações em produtos e processos, das oportunidades para expandir ou desenvolver novos mercados com serviços personalizados e assim por diante. Nessas organizações, a informatização será um processo essencial. Mas para que a informatização se torne uma estratégia consciente, será necessário criar uma visão que transcenda as limitações de nossa linguagem corrente. As imagens associadas ao trabalho físico não podem mais guiar nossa concepção de trabalho. O local de trabalho, que pode não mais ser um "lugar", poderá vir a ser pensado como uma arena através da qual circulam informações às quais o esforço intelectivo é aplicado. A qualidade, não a quantidade, do esforço é a fonte do valor adicionado. Os economistas podem continuar a medir a produtividade do trabalho como se o mundo inteiro pudesse ser adequadamente simbolizado pela linha de montagem, mas 
suas medidas provavelmente serão sistematicamente indiferentes ao que é mais valioso numa organização informatizada.

Um mundo como esse necessita de um novo vocabulário, que introduza as possibilidades de colegas e co-aprendizes, exploração, experimentação e inovação; que desalva cargos que são abrangentes, tarefas que são abstrações, dependentes da perspicácia e da síntese, e o poder, que é uma força errante que se torna inativa segundo a função e a necessidade. Um novo vocabulário não pode ser imposto; ele terá que ser desenvolvido por aqueles que estão empenhados em quebrar os laços com a lógica industrial que tem governado a vida imaginativa de nosso século.

A tecnologia industrial tem sido libertadora; ela criou uma vasta riqueza e diminuiu as exigências sobre o corpo humano. Ela tem sido também sedutora prometendo realizar o sonho da automação perfeita ao mesmo tempo que cura egos machucados pela necessidade de certeza e controle. Parte do sonho é uma imagem de "pessoas servindo uma máquina inteligente". Na sombra do sonho, os seres humanos têm perdido a experiência do julgamento crítico. Mas somente esse julgamento pode iniciar o tipo de ação humana que move sobre e contra o vórtice do estímulo, não meramente para responder, mas para "saber melhor que", para perguntar, para inventar, para dizer não. O sonho da automação nos aproxima perigosamente da visão sombria de Hannah Arendt de um mundo behaviorista que se torna realidade: "O último estágio da sociedade laboriosa, a sociedade das pessoas que têm emprego, exige de seus membros um funcionamento simplesmente automático, como se a vida individual tivesse verdadeiramente submergido no processo global da vida das espécies e a única decisão ativa, ainda requerida do indivíduo, fosse a de desistir ou, por assim dizer, abandonar sua individualidade, a dor e o problema de viver ainda individualmente sentidos, e consentir num tipo de comportamento atordoado, "tranqüilizado", funcional. O problema com as teorias modernas de behaviorismo não é o fato de que estejam erradas, mas o fato de que poderiam tornar-se realidade, que elas são realmente a melhor conceitualização possível de certas tendências óbvias da sociedade moderna. É muito concebivel que a idade moderna - que começou com um surto promissor e sem precedentes de atividade humana- possa terminar na mais mortífera e estéril passividade que a história já conheceu."

E o mais perturbador é que os próprios administradores possam ceder a esse sonho por inércia ou conveniência, não por uma análise convincente. As organizações que adotam uma estratégia puramente automatizante podem estabelecer um trajeto que não é facilmente reversível. A mensagem comunicada à força de trabalho e o esgotamento das qualificações que seriam necessárias nas atividades que adicionam valor representam perdas que não são facilmente recuperáveis.

Uma estratégia informatizante requer uma visão abrangente que avalie as possibilidades únicas da tecnologia inteligente e que reconheça a necessidade de utilizar a organização para liberar essas possibilidades. Significa forjar uma nova lógica de utilização da tecnologia baseada nessa visão. Um fundamento lógico coerente será necessário, particularmente quando a tendência do pensamento convencional e suposições familiares começarem a submergir às várias escolhas importantes, carregadas de valor, relacionadas ao perfil básico da tecnologia. Como um administrador de uma fábrica salientou: "A tecnologia está indo na direção em que uma pessoa opera o controle central. A tecnologia está certa? Nós não acreditamos que esteja, e estamos trabalhando muito para convencer os vendedores a deixarem o projeto suficientemente flexivel a fim de que ele não impeça os usos que queremos fazer dela."

A organização informatizada se move numa outra direção. Ela se baseia nas capacidades humanas de ensinar e aprender, em críticas e em idéias. Ela tem uma abordagem para a melhoria dos negócios que reside na inovação possibilitada pela maior compreensão dos processos centrais. $\mathrm{E}$ ela reflete $a$ interdependência entre a mente humana e algumas de suas produções mais sofisticadas. Como um trabalhador ponderou: "Se você não deixa as pessoas crescerem, desenvolverem-se e tomarem decisões, é um desperdício da vida humana - uma perda do potencial humano. Se você não usa seu conhecimento e qualificações, é um desperdício da vida. Usar as novas tecnologias em todo seu potencial significa usar a pessoa em seu pleno potencial."

\section{8}

Tradução de Angelo Soares Doutorando em Sociologia do Trabalho na Université Laval, revista por Geni Goldschmidt, Socióloga. Artigo publicado originalmente sob o título $\mathrm{Au}$ tomate/Informate: the two faces of intelligent technology, pela Organizational Dynamics, American Management Association, New York, NY, EUA. 